JURNAL ILMIAH AGRINECA

ISSN : 2721-074X (Online) - 2301-6698 (Print)

Available on : http://ejournal.utp.ac.id/index.php/AFP/index

This is Under CC BY SA Licence

\title{
KARAKTER PERAKARAN DAN HASIL BERBAGAI VARIETAS PADI SAWAH (Oryza sativa L.) DENGAN APLIKASI MIKORIZA PADA LAHAN SAWAH TADAH HUJAN
}

\author{
Root Characters and Yield Varieties of Paddy with Micorrhyza \\ Application on Rainfed Lowland Rice
}

\author{
Joko Prianto, Achmad Fatchul Aziez*, dan Setie Harieni \\ Program Studi Agroteknologi, Fakultas Pertanian, Universitas Tunas Pembangunan \\ Surakarta \\ *Corresponden author: achmad.aziez@yahoo.com
}

\begin{abstract}
Rice (Oryza sativa L.) is a food commodity that has a very important role and is the main food commodity in Indonesia. One attempt to increase rice production through rice cultivation techniques by adding mycorrhizae to plants. Root is the most important part of plants that are in the soil and has a very important role and absorbs water and nutrients. This study aims to determine the effect of mycorrhizal on the character of roots and the results of rice paddy varieties cultivated on rainfed land. This research was conducted in January 2018 until July 2018 in Demangan village, Sambi sub-district, Boyolali district. With rainfed rice fields and $130 \mathrm{mplpl}$ altitude with Regosol soil types and the Laboratory of Soil Science, Faculty of Agriculture, Tunas Pembangunan Surakarta University and at the Plant Sciences Laboratory, Faculty of Agriculture, Gadjah Mada University, Yogyakarta. This study uses a Complete Randomized Block Design (RAKL) arranged in a split plot with two factors, namely mycorrhiza as main plot and varieties as sub-plots and repeated three times with mycorrhizal levels as follows; MO: without mycorrhiza, M1: with mycorrhiza and varieties with the following levels; V1: situbagendit varieties, V2: pepe varieties, V3: mentikwangi varieties, V4: varieties of way apo parah, V5: memberamo varieties, V6: mekongga varieties, V7: varieties IR 64, V8: inpari varieties13. The results of this study indicate that: (1) the treatment of mycorrhizal use in rice plants showed significantly different effects on root length, surface area, fresh and dry weight of roots, plant dry weight and weight of harvested dry paddy / plot. (2) The treatment of various rice varieties is a way to find out the best varieties. The best varieties are memberamo varieties because they can be infected with mycorrhizae very effectively. (3) The highest yield of harvested dry grain / hectare was found in MIVI with the treatment of $3.725 \mathrm{~kg}$ memberamo variety mycorrhizal, and the lowest yield of dry grain / plot weight was in MOV7 with mycorrhizal treatment of IR 64 varieties weighing $1,956 \mathrm{~kg}$.
\end{abstract}

Keywords: mycorrhizae, rice, roots, varieties.

\section{ABSTRAK}

Padi (Oryza sativa L) merupakan komoditas pangan yang sangat penting peranannya dan menjadi komoditas utama pangan di indonesia. Salah satu upaya untuk meningkatkan produksi padi melalui teknik budidaya padi dengan menambahkan mikoriza pada tanaman. Akar adalah bagian terpenting pada tanaman yang berada didalam tanah dan memiliki peran yang sangat penting dan menyerap air dan unsur hara. Penelitian ini bertujuan untuk mengetahui pengaruh mikoriza terhadap karakter perakaran dan hasil varietas padi sawah yang dibudidayakan pada lahan tadah hujan. Penelitian ini dilaksanakan pada bulan Januari 2018 sampai dengan Juli 2018 di di desa Demangan, kecamatan Sambi, kabupaten Boyolali. Dengan lahan sawah tadah hujan dan ketinggian tempat 130 mdpl dengan jenis tanah Regosol dan Laboratorium Ilmu Tanah Fakultas Pertanian Universitas Tunas Pembangunan Surakarta dan di Laboratorium Ilmu Tanaman Fakultas Pertanian Universitas Gadjah Mada Yogyakarta. Penelitian ini menggunakan Rancangan Acak Kelompok Lengkap (RAKL) yang disusun secara Split Plot dengan dua faktor yaitu mikoriza sebagai main plot dan varietas sebagai sub plot dan diulang tiga kali dengan taraf mikoriza sebagai berikut ; M0 : tanpa mikoriza, M1 


\section{AGRINECA}

JURNAL ILMIAH AGRINECA

ISSN : 2721-074X (Online) - 2301-6698 (Print)

Available on : http://ejournal.utp.ac.id/index.php/AFP/index

This is Under CC BY SA Licence

: dengan mikoriza dan varietas dengan taraf sebagai berikut; V1 : varietas situbagendit, V2 : varietas pepe, V3 : varietas mentikwangi, V4 : varietas way apo buru, V5 : varietas memberamo, V6 : varietas mekongga, V7 : varietas IR 64, V8 : varietas inpari13. Hasil penelitian ini menunjukkan bahwa : (1) perlakuan penggunaan mikoriza pada tanaman padi menunjukkan berpengaruh berbeda nyata terhadap panjang akar, luas permukaan, berat segar dan kering akar, berat kering tanaman dan berat gabah kering panen/petak. (2) Perlakuan berbagai varietas tanaman padi merupakan cara untuk mengetahui varietas terbaik. Varietas yang terbaik adalah varietas memberamo karena dapat terinfeksi mikoriza dengan sangat efektif. (3) Hasil tertinggi berat gabah kering panen/hektar terdapat pada M1V1 dengan perlakuan dengan mikoriza varietas memberamo dengan berat $3.725 \mathrm{~kg}$, dan hasil terendah berat gabah kering panen/petak terdapat pada M0V7 dengan perlakuan tanpa mikoriza varietas IR 64 dengan berat $1.956 \mathrm{~kg}$.

Kata kunci : akar, mikoriza, padi, varietas. 


\section{PENDAHULUAN}

Padi merupakan tanaman pangan yang awalnya berasal dari pertanian kuno dari benua Asia dan Afrika Barat tropis dan subtropis. Bukti sejarah menunjukkan bahwa pertanaman padi di Zhenjiang (Cina) sudah dimulai pada 3.000 tahun SM dan ditemukannya fosil butiran padi dan gabah di Hastinapur Uttar Pradesh India sekitar 100 - 800 tahun SM (Purwono dan Heni Purnamawati. 2009).

Di Indonesia padi menempati posisi sebagai tanaman pangan strategis. Sejalan dengan pertambahan penduduk, kebutuhan beras setiap tahunnya terus meningkat sehingga produksi padi harus ditingkatkan. Salah satu permasalahan yang kini dihadapi para petani adalah menurunya kesuburan lahan (Hariyadi, Huda, Ali, \& Wandik, 2019). Permasalahan ini secara umum disebabkan karena dipacunya lahan untuk berproduksi semaksimal mungkin secara terus menerus untuk mengejar peningkatan produktivitas (Rahmatika, 2010). Kebutuhan akan beras terus meningkat dari tahun ke tahun akibat terjadinya peningkatan konsumsi dan jumlah penduduk. Kebutuhan beras pada tahun 2018, perkiraan produksi padi di Indonesia sebanyak 56,54 juta ton Gabah Kering Giling (GKG) atau setara dengan 32,42 juta ton beras (Badan Pusat Statistik, 2018).

Akar tanaman padi berfungsi sebagai penguat/penunjang tanaman untuk dapat tumbuh tegak, menyerap hara dan air dari dalam tanah untuk selanjutnya diteruskan ke organ lainnya di atas tanah. Akartanaman padi termasuk golongan akar serabut, akar primer (radikula) yang tumbuh sewaktu berkecambah bersama akar-akar lain yangmuncul dari janin dekat bagian buku skutellum disebut akar seminalyang jumlahnya antara 1-7 (Makarim dan Suhartatik, 2009).

Kondisi lahan kering mengakibatkan sulitnya membudidaya kan berbagai produk pertanian. Faktor primer yang diperlukan tanaman untuk tumbuh adalah media tanam, air, cahaya, angin, dan nutrisi tanaman. Semua faktor yang diperlukan tanaman untuk dapat tumbuh dengan baik tersebut terhambat oleh kondisi daerah lahan kering yang memiliki iklim dan cuaca ekstrim. Salah satu faktor pertumbuhan yaitu air, jika ketersediaannya terbatas dapat menjadi kendala bagi pertanian. Solusi yang dapat dilakukan yaitu dengan pengkondisian tanah (soil amendment), mulsa, maupun sistem irigasi tepat guns (Mutowal, 2013).

Mikoriza adalah salah satu jenis pupuk hayati yang berperan terhadap peningkatan kesehatan tanah, ramah lingkungan dan mampu meningkatkan status hara tanah serta hasil pertanian. Jamur mikoriza dapat berpengaruh cukup besar pada sistem akar padi. Hifa jamur dapat memperluas daerah penyerapan akar yang disebabkan karena hifa yang sangat banyak dan lebih tipis dari rambut akar, sehingga dapat mengakses air dan nutrisi di pori-pori terkecil tanah dan celah-celahnya. Akses pori - pori tanah dikombinasikan dengan kemampuan mikoriza untuk mencapai tanah di sekitarnya hingga 18 24 inci lebih jauh daripada akar tanpa mikoriza pada tanaman padi dalam efisiensi peningkatan hara dan kemampuan pnyerapan air. (Amaranthus 2013).

\section{METODE PENELITIAN}

Penelitian ini dilaksanakan pada bulan Januari 2018 sampai dengan Juli 2018 di di desa Demangan, kecamatan Sambi, kabupaten Boyolali. Dengan lahan sawah tadah hujan dan ketinggian tempat 130 mdpl dengan jenis tanah Regosol dan Laboratorium Ilmu Tanah Fakultas Pertanian Universitas Tunas Pembangunan Surakarta dan di Laboratorium Ilmu Tanaman Fakultas Pertanian Universitas Gadjah Mada Yogyakarta.

Penelitian ini menggunakan Rancangan Acak Kelompok Lengkap (RAKL) yang disusun secara Split Plot dengan dua faktor dan diulang tiga kali. Mikoriza (M) sebagai Main Plot (petak utama) terdiri 2 taraf perlakuan yaitu: M0 : Tanpa Mikoriza, M1 : Dengan Mikoriza. Macam varietas padi (V) sebagai Sub Plot (anak petak) terdiri dari 8 taraf yaitu: V1 : Varietas Situbagendit, V2 : Varietas Pepe, V3 Varietas Mentikwangi, V4 Varietas Way Apo Buru, V5 : Varietas Memberamo, V6 : Varietas Mekongga, V7 : Varietas IR 64, V8 : Varietas Inpari 31.

Parameter yang diamati adalah Panjang akar total $(\mathrm{cm})$, Luas permukaan akar $\left(\mathrm{cm}^{2}\right)$, 
JURNAL ILMIAH AGRINECA

ISSN : 2721-074X (Online) - 2301-6698 (Print)

Available on : http://ejournal.utp.ac.id/index.php/AFP/index

This is Under CC BY SA Licence

Volume akar $\left(\mathrm{cm}^{3}\right)$, Berat segar akar $(\mathrm{g})$, Berat kering akar (g), Berat kering tanaman (g), Berat gabah kering panen /Petak $(\mathrm{kg})$. ASIL DAN PEMBAHASAN

Tabel 1 Uji Lanjut BNT 5\%. Karakter perakaran berbagai macam varietas padi sawah (Oryza sativa L.) Dengan Aplikasi Mikoriza Pada Lahan Sawah Tadah Hujan Terhadap Pertumbuhan Tanaman.

Parameter Pertumbuhan

\begin{tabular}{|c|c|c|c|}
\hline Perlakuan & $\begin{array}{l}\text { Panjang } \\
\text { akar total } \\
(\mathrm{cm})\end{array}$ & $\begin{array}{c}\text { Luas } \\
\text { permukaan } \\
\text { akar }\left(\mathrm{cm}^{2}\right)\end{array}$ & $\begin{array}{c}\text { Volume } \\
\text { akar }\left(\mathrm{cm}^{3}\right)\end{array}$ \\
\hline \multicolumn{4}{|r|}{ Mikoriza (M) } \\
\hline M0 & $634,50 \mathrm{~b}$ & $498,25 \mathrm{~b}$ & $20,27 \mathrm{~b}$ \\
\hline M1 & $744,08 \mathrm{a}$ & $550,97 \mathrm{a}$ & $23,27 \mathrm{a}$ \\
\hline \multicolumn{4}{|c|}{ Varietas Tanaman Pac } \\
\hline V1 & $568,00 \mathrm{~b}$ & $406,58 \mathrm{c}$ & $20,08 \mathrm{c}$ \\
\hline $\mathrm{V} 2$ & $756,50 \mathrm{a}$ & $424,43 \mathrm{bc}$ & $21,83 \mathrm{~b}$ \\
\hline V3 & $651,33 \mathrm{~b}$ & $437,64 \mathrm{~b}$ & $21,21 \mathrm{bc}$ \\
\hline V4 & $693,33 \mathrm{ab}$ & $400,98 \mathrm{c}$ & $20,21 \mathrm{c}$ \\
\hline V5 & $828,33 \mathrm{a}$ & $707,30 \mathrm{a}$ & $24,96 \mathrm{a}$ \\
\hline V6 & $722,33 \mathrm{a}$ & $498,93 \mathrm{~b}$ & $21,88 \mathrm{~b}$ \\
\hline V7 & $578,67 \mathrm{~b}$ & $421,75 \mathrm{c}$ & $22,83 \mathrm{ab}$ \\
\hline V8 & $715,83 \mathrm{a}$ & $539,25 \mathrm{ab}$ & $21,58 \mathrm{~b}$ \\
\hline
\end{tabular}

berbeda nyata. Interaksi perlakuan mikoriza dengan beberapa varietas tidak menunjukkan berbeda nyata. Interaksi yang terbaik adalah M1V5 dengan rata - rata 906,0 cm sedangkan yang terendah adalah M0V7 dengan rata - rata $451,0 \mathrm{~cm}$.

Tanaman yang terinfeksi jamur mikoriza akan menunjukkan panjang akar yang lebih baik ila dibandingkan dengan tanaman yang tidak terinfeksi mikoriza, pemberian mikoriza

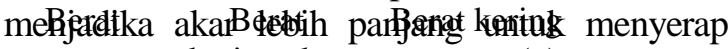

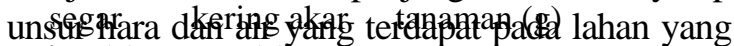
kekfaly.g) Menurgtt Purwaningsih (2011), peningkatan penyerapan unsur hara terjadi dengan

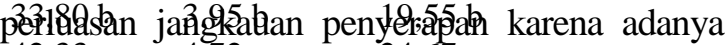
hifa 3 eksternat, Yaung dapat 24 mencapai $8 \mathrm{~cm}$ di luar sisistem perakaran, eksploitasi sampai ke pori mikro

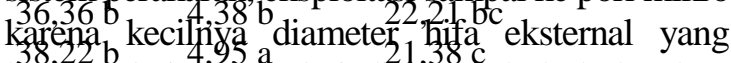
ky,ang dari 5,03 a dari dian,eter bulu-bulu akar,

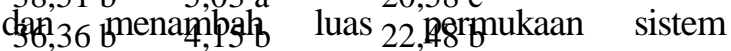
pez,serapan. 5,58 a $\quad 25,81$ a

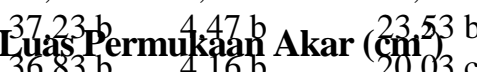

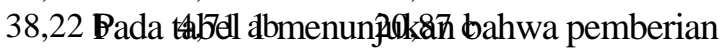

Interaksi Antara Mikoriza dan Varietasnficolqzan Pbeipedyaruh nyata terhadap luas

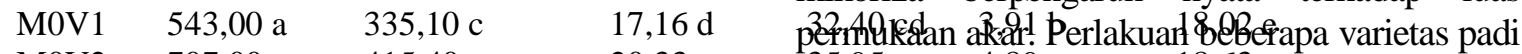

M0V2 707,00 a $\quad 415,40 \mathrm{c} \quad 20,33 \mathrm{c}$

M0V3 597,30 a $\quad 349,80 \mathrm{c} \quad 18,66 \mathrm{~cd}$

M0V4 680,30 a $\quad 409,60 \mathrm{c} \quad 19,76 \mathrm{c}$

M0V5 750,60 a $\quad 527,40 b \quad 21,76 b$

M0V6 698,30 a $\quad 435,80 \mathrm{~b} \quad 21,33 \mathrm{~b}$

M0V7 451,00 a $\quad 304,10 \mathrm{c} \quad 22,50 \mathrm{~b}$

M0V8 651,30 a $\quad 488,40 \mathrm{~b} \quad 20,66 \mathrm{bc}$

M1V1 593,00 a $\quad 478,00 \mathrm{~b} \quad 23,00 \mathrm{~b}$

M1V2 806,00 a $\quad 433,40$ bc $\quad 23,33$ b

M1V3 705,30 a $525,40 b \quad 23,76 b$

M1V4 706,30 a $392,30 b \quad 20,66$ bc

M1V5 906,00 a $\quad 887,10$ a $\quad 28,16$ a

M1V6 749,30 a $\quad 562,00 \mathrm{~b} \quad 22,43 \mathrm{~b}$

M1V7 706,30 a $539,30 b \quad 23,16 b$

M1V8 780,30 a 590,10 b $\quad 22,50$ b

Keterangan : Perlakuan yang diikuti dengan satu huruf yang sama menunjukkan berbeda tidak nyata menurut uji BNT antar perlakuan dengan taraf $5 \%$.

\section{Panjang Akar Total (cm)}

Hasil sidik ragam pada tabel 1 menunjukan bahwa pemberian mikoriza berpengaruh nyata terhadap panjang akar total. Perlakuan beberapa varietas padi sawah menunjukkan pengaruh yang

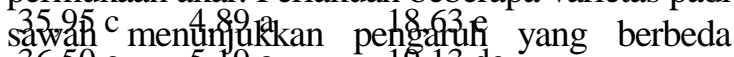

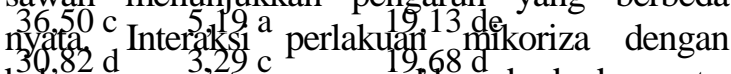
beberapa varietas menunjukkan berbeda nyata.

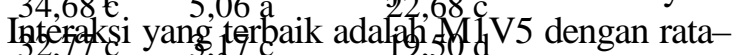
rata, 2287,1 ç,70sedangkan \&,498 terendah adalah B4Q, $\$ 3$ dengan,Gatg-rata $3020,30 \mathrm{na}^{2}$.

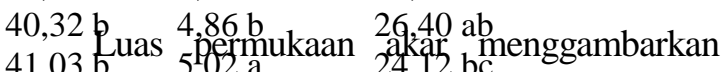
ke,03 5 puan 5 akar dalam men,yerap unsur hara dan air , 90 falam,tanah, semakij, 2lols area perakaran ngak,38 area pe,oserapan unsu,ghara dan air akan men,jedi sem,

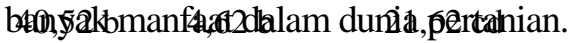

$42,38 \mathrm{~b} \quad 4,77 \mathrm{~b}_{3} \quad 21,43 \mathrm{~d}$

Pada tabel 1 menunjukan bahwa pemberian mikoriza berpengaruh nyata terhadap volume akar. Perlakuan beberapa varietas padi sawah menunjukkan pengaruh yang berbeda nyata. Interaksi perlakuan mikoriza dengan beberapa varietas menunjukkan berbeda nyata. Interaksi yang terbaik pada volume akar adalah M1V5 dengan rata - rata $28,16 \mathrm{~cm}^{3}$ sedangkan yang 
JURNAL ILMIAH AGRINECA

ISSN : 2721-074X (Online) - 2301-6698 (Print)

Available on : http://ejournal.utp.ac.id/index.php/AFP/index

This is Under CC BY SA Licence

terendah adalah M0V1 dengan rata-rata 17,16 $\mathrm{cm}^{3}$.

Volume akar sangat mempengaruhi dalam proses akar menyerap kebutuhan air dan unsur hara untuk kelangsungan hidup tanaman. Volume akar dipengaruhi oleh perbedaan genotipe dan sistem pengairan (Munarso 2011). Tanaman dengan volume akar yang besar akan mampu mengabsorbsi air lebih banyak sehingga mampu bertahan pada kondisi kekurangan air (Palupi dan Dedywiryanto 2008).

\section{Berat Segar Akar (g)}

Pada tabel 1 menunjukan bahwa pemberian mikoriza berpengaruh nyata terhadap berat segar akar. Perlakuan beberapa varietas padi sawah menunjukkan pengaruh yang berbeda nyata. Interaksi perlakuan mikoriza dengan beberapa varietas menunjukkan berbeda. Interaksi yang terbaik pada berat segar akar adalah M1V5 dengan rata - rata 50,38 gram sedangkan yang terendah adalah M0V1 dengan rata - rata 32,40 gram.

Sebagai salah satu organ tanaman, akar berperan penting pada saat tanaman merespons kekurangan air dengan cara mengurangi laju transpirasi untuk menghemat air. Pada umumnya tanah mengering dari permukaan tanah hingga ke lapisan tanah bawah selama musim kemarau. Keadaan ini menghambat pertumbuhan akar di lapisan tanah yang dangkal, karena sel-selnya tidak dapat mempertahankan turgor yang diperlukan untuk pemanjangan. Akar yang terdapat di lapisan tanah lebih dalam masih dikelilingi oleh tanah yang lembab, sehingga akar tersebut akan terus tumbuh. Dengan demikian sistem akar akan memperbanyak diri dengan cara memaksimumkan pemaparan air tanah (Campbell, Reece JB, dan Mitchell. 2003).

\section{Berat Kering Akar (g)}

Pada tabel 1 menunjukan bahwa pemberian mikoriza berpengaruh nyata terhadap berat kering akar. Perlakuan beberapa varietas padi sawah menunjukkan pengaruh yang berbeda nyata. Interaksi perlakuan mikoriza dengan beberapa varietas menunjukkan berbeda. Interaksi terbaik pada berat kering akar adalah M1V5 dengan rata - rata 6,09 gram sedangkan yang terendah adalah M0V6 dengan rata - rata 3,17 gram.

Berat kering akar mewakili pertumbuhan organ tanaman yang berada di bawah permukaan tanah, yang mempengaruhi perkembangan organ diatasnya. Tumbuhan dianggap memiliki sistem rooting yang baik jika mereka memiliki akar kering yang baik rasio berat / mahkota. Berat kering akar juga mewakili jumlah asimilasi itu didistribusikan ke sistem rooting. Hasil asimilasi yang dihasilkan di daun akan ditranslokasikan ke seluruh tubuh tanaman melalui jaringan pengangkut. Hal ini didukung dengan data pada irigasi berselang varietas terbaik adalah mentikwangi diperoleh berat kering akar $36.25 \mathrm{~g}$, sedangkan pada irigasi berkelanjutan varietas terbaik adalah sintanur diperoleh 31.70 g. (Aziez, Hanudin, dan S. Harieni 2018).

\section{Berat Kering Tanaman (g)}

Pada tabel 1 menunjukan bahwa pemberian mikoriza berpengaruh nyata terhadap berat kering tanaman. Perlakuan beberapa varietas padi sawah menunjukkan pengaruh yang berbeda nyata. Interaksi perlakuan mikoriza dengan beberapa varietas menunjukkan berbeda. Interaksi terbaik pada berat kering tanaman.

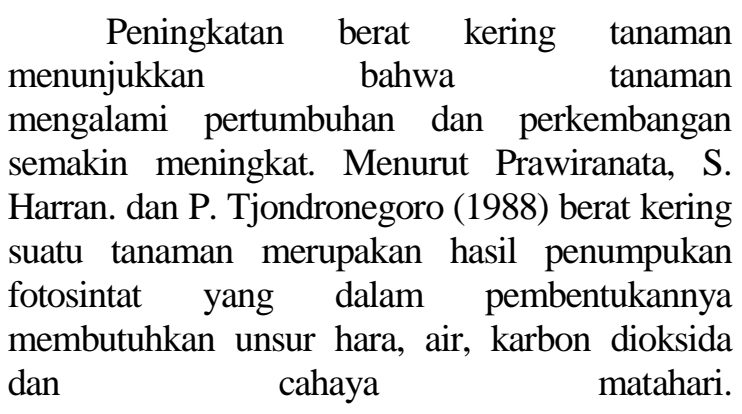

Tabel 2 Uji Lanjut BNT 5\%. Karakter perakaran berbagai macam varietas padi sawah (Oryza sativa L.) Dengan Aplikasi Mikoriza Pada Lahan Sawah Tadah Hujan Terhadap Hasil Tanaman.

\section{Parameter Hasil}




\begin{tabular}{|c|c|}
\hline \multicolumn{2}{|c|}{$\begin{array}{c}\text { JURNAL ILMIAH AGRINECA } \\
\text { ISSN }: 2721-074 X \text { (Online) - 2301-6698 (Print) } \\
\text { Available on }: \frac{\text { http://ejournal.utp.ac.id/index.php/AFP/index }}{\text { This is Under CC BY SA Licence }}\end{array}$} \\
\hline \multicolumn{2}{|c|}{ Mikoriza } \\
\hline M1 & $3,95 \mathrm{~b}$ \\
\hline M2 & $4,72 \mathrm{a}$ \\
\hline \multicolumn{2}{|c|}{ Varietas Tanaman Padi } \\
\hline V1 & $4,55 \mathrm{~b}$ \\
\hline V2 & $4,58 \mathrm{~b}$ \\
\hline V3 & $4,18 \mathrm{~b}$ \\
\hline V4 & $4,11 \mathrm{~b}$ \\
\hline V5 & $5,36 \mathrm{a}$ \\
\hline V6 & $4,06 \mathrm{bc}$ \\
\hline V7 & $3,56 \mathrm{c}$ \\
\hline V8 & $4,30 \mathrm{~b}$ \\
\hline \multicolumn{2}{|c|}{ Interaksi Antara Mikoriza dan Varietas Tanaman Padi (MV) } \\
\hline M0V1 & $4,50 \mathrm{c}$ \\
\hline M0V2 & $3,63 \mathrm{~cd}$ \\
\hline M0V3 & $4,26 \mathrm{c}$ \\
\hline M0V4 & $3,60 \mathrm{~d}$ \\
\hline M0V5 & $4,76 \mathrm{~b}$ \\
\hline M0V6 & $3,53 \mathrm{~d}$ \\
\hline M0V7 & $3,13 \mathrm{~d}$ \\
\hline M0V8 & $4,23 \mathrm{c}$ \\
\hline M1V1 & $4,60 \mathrm{bc}$ \\
\hline M1V2 & $5,53 \mathrm{a}$ \\
\hline M1V3 & $4,10 \mathrm{c}$ \\
\hline M1V4 & $4,63 \mathrm{~b}$ \\
\hline M1V5 & $5,96 \mathrm{a}$ \\
\hline M1V6 & $4,60 \mathrm{bc}$ \\
\hline M1V7 & $4,00 \mathrm{c}$ \\
\hline M0V8 & $4,36 \mathrm{c}$ \\
\hline
\end{tabular}

Keterangan : Perlakuan yang diikuti dengan satu huruf yang sama menunjukkan berbeda tidak nyata menurut uji BNT antar perlakuan dengan taraf 5\%.

\section{Berat Gabah Kering Panen / Petak (kg)}

Pada Tabel 2 menujukan hasil pemberian mikoriza berbeda nyata pada parameter berat gabah kering panen per petak. Perlakuan beberapa varietas padi sawah menunjukkan pengaruh yang berbeda nyata. Interaksi perlakuan mikoriza dengan beberapa varietas menunjukkan berbeda. Interaksi terbaik pada berat gabah kering panen per petak adalah M1V5 dengan rata - rata $5,96 \mathrm{~kg}$ sedangkan yang terendah adalah M0V7 dengan rata - rata $3,13 \mathrm{~kg}$.

Berat gabah kering panen menunjukkan hasil ekonomi yang diperoleh dalam budidaya pertanian, penggunaan mikoriza sendiri dapat mempengaruhi hasil dari tanaman. Menurut Haris dan Adnan (2000) manfaat penambahan cendawan mikoriza antara lain: pertumbuhan tanaman menjadi lebih baik sehingga hasil yang didapat jauh lebih banyak. Hal ini karena mikoriza dapat meningkatkan luasan penyerapan hara oleh miselium eksternal. Mikoriza dapat meningkatkan lingkungan mikrorisosfer yang dapat merubah komposisi dan aktivitas mikroba tanah. Hal ini karena terjadi perubahan fisiologi akar dan produksi sekresi oleh mikroba.

\section{KESIMPULAN}

Penggunaan mikoriza pada tanaman padi (Oryza sativa L.) menunjukkan berpengaruh berbeda nyata terhadap panjang akar, luas permukaan, berat segar dan kering akar, berat kering tanaman dan berat gabah kering panen/petak.

Perlakuan berbagai varietas tanaman padi merupakan cara untuk mengetahui varietas terbaik. Varietas yang terbaik berdasarkan hasil adalah varietas memberamo, sedangkan varietas 


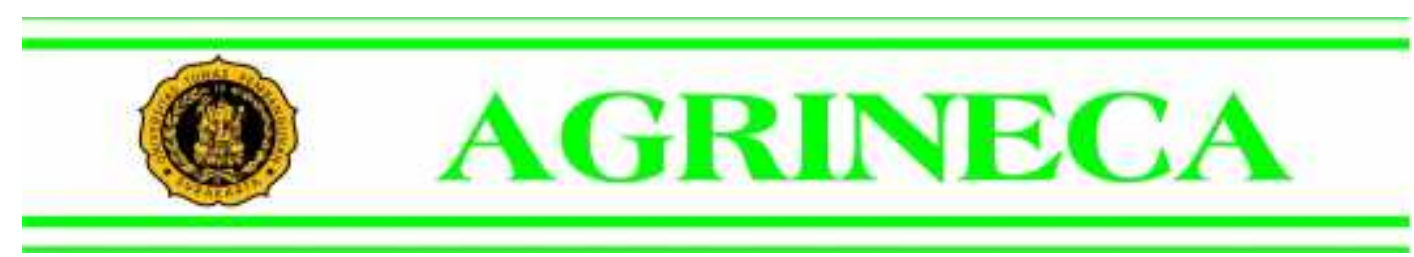

JURNAL ILMIAH AGRINECA

ISSN : 2721-074X (Online) - 2301-6698 (Print)

Available on : http://ejournal.utp.ac.id/index.php/AFP/index

This is Under CC BY SA Licence

terbaik berdasarkan ketahanan terhadap kekeringan adalah varietas situbagendit.

Hasil tertinggi berat gabah kering panen/ha terdapat pada M1V1 dengan perlakuan dengan mikoriza varietas memberamo dengan berat 3.725 $\mathrm{kg}$, dan hasil terendah berat gabah kering panen/petak terdapat pada M0V7 dengan perlakuan tanpa mikoriza varietas IR 64 dengan berat $1.956 \mathrm{~kg}$.

\section{DAFTAR PUSTAKA}

Amaranthus M. 2013. Mycorrhizal Fungi, Getting To Thee Root Of Soybean Success. URL: http://mycorrhizae.com/wpcontent/uploads/Getting-to-the-Root-ofSoybean-success.pdf. Diakses pada 16 Maret 2019.

Aziez, A. F., E. Hanudi, and S. Harieni. 2018. Impact of Water Management on Root Morphology, Growth and Yield Component Varieties of Lowland Rice under the Organic System of Rice Intensification. Journal Of Degraded And Mining Lands Management. V(2) : 1035-1045. 2 Januari $2018 . \quad$ DOI: 10.15243/jdmlm.2018.052.1035

Campbell NA, Reece JB, Mitchell LG. 2003. Biologi. Jilid ke-dua. Edisi ke-lima. Erlangga, Jakarta

Haris A dan Adnan AM 2000. Mikoriza dan Manfaatnya. Balai Penelitian Tanaman Serelia. Prosiding Seminar Ilmiah dan Pertemuan Tahunan PEI dan PFI XVI Komda Sul-Sel.

Hariyadi, B. W., Huda, N., Ali, M., \& Wandik, E. (2019). The Effect of Tambsil Organic Fertilizer on The Growth And Results of Onion (Allium Ascalonicum L.) In Lowland.
Agricultural Science, 2(2), 127-138.

Makarim dan Suhartatik. 2009. Morfologi dan Fisiologi Tanaman Padi. Balai Besar Penelitian Tanaman Padi. Sukabumi. Subang.

Munarso PY (2011) Keragaan padi hibrida pada sistem pengairan intermittent dan tergenang. Penelitian Pertanian Tanaman Pangan 30:189195

Mutowal W. 2013. Kendala pertanian lahan kering dan solusinya. URL: http://grobogan.go.id/info/artikel/562-kendalapertanian-lahan-kering-dan-solusinya. Diakses pada 16 Maret 2019.

Palupi ER, Dedywiryanto Y. 2008. Kajian karakter toleransi cekaman kekeringan pada empat genotipe bibit kelapa sawit (Elaeis guineensis Jacq). Bul Agron 36(1): 24-32

Prawiranata, W., S. Harran. dan P. Tjondronegoro. 1988. Dasar-Dasar Fisiologi Tumbuhan. Departemen Botani Fakultas Pertanian IPB. Bogor. 313 hal.

Purnamaningsih, Ragapadmi. 2006. Induksi Kalus dan Optimasi Regenerasi Empat Varietas Padi Melalui Kultur In Vitro. Balai Besar Penelitian dan Pengawasan Bioteknologi dan Sumber Daya Genetik Pertanian. Bogor. Jurnal AgroBiogen 2(2):74-80.

Purwono dan Heni Purnamawati. 2009. Budidaya 8 Jenis Tanaman Pangan Unggul. Penebar Swadaya:Jakarta.

Rahmatika, W. 2010. Pertumbuhan tanaman padi (Oryza sativa L.) akibat pengaruh persentase N (Azolla dan Urea). Primordia Volume 6, Nomor 2, Juli 2010. 